\title{
Safe Motherhood in South Asia: Current Status and Strategies for Change
}

\author{
ZebA A. SATHAR and BILQUEes RAZA
}

\section{INTRODUCTION}

Women in South Asia comprise close to one third of the world's female population. Not only is South Asia an extremely populous region but population growth rates have been much higher than averages for other developing countries. The implications of high population growth rates are quite direct and severe for women, as they are the result of high levels of fertility which have prevailed for some time in this region. The stable and high levels of fertility along with falling mortality have led to a youthful population structure where about 45 percent of the population is aged under 15 . Since childbearing as well as childrearing are almost the sole responsibility of women, these figures reflect the burden of high fertility amongst South Asian women.

An average South Asian woman marries at a fairly young age, (even though the region is exhibiting a distinct trend of rising age at marriage for females) and starts bearing children soon after. Though fertility rates have been declining in most of India and Bangladesh while they had already reached quite low levels in Sri Lanka, other countries of the region (mainly Nepal and Pakistan) have still to experience any dramatic declines in fertility. In contrast with trends in the Latin American and South East Asian region, increases in contraceptive use in South Asia have not played as substantive a role in fertility declines as changing marriage patterns, atleast so far. See Table 1 for recent figures on fertility and contraceptive use among females of this region.

Contraceptive use rates in this region, with the exception of Sri Lanka, remain far lower than the average of less developed countries which is 45 percent. Though India and Bangladesh have achieved moderate levels of contraceptive use, the levels of contraceptive prevalence are almost negligible in Nepal and particularly Pakistan. 
Table 1

Total Fertility Rates and Contraceptive Use in Selected Countries of the SAARC Region

\begin{tabular}{lcc}
\hline Country & $\begin{array}{c}\text { Total Fertility Rates } \\
(\mathbf{1 9 9 1 )}\end{array}$ & $\begin{array}{c}\text { Percentage of Married } \\
\text { Women of Child Bearing } \\
\text { Age Using Contraception } \\
(1989)^{1}\end{array}$ \\
\hline Bangladesh & 4.4 & 31 \\
Bhutan & 5.9 & Not Available \\
India & 3.9 & 45 \\
Nepal & 5.5 & 14 \\
Pakistan & 5.7 & 12 \\
Sri Lanka & 2.5 & 62 \\
\hline
\end{tabular}

Source: ${ }^{1}$ World Development Report (1993).

UNICEF (1992) The State of the World's Children. Tables 5 and 7.

Apart from high fertility rates (except in Sri Lanka), another distinct characteristic of the South Asian region is the higher mortality experienced by females of this region. Given the advantage in mortality that females experience in most parts of the world where their life expectancy is much higher than that of males of equivalent societies, it is an outstanding reflection of the poorer health status of females that in this region the differential in mortality is in the opposite direction. Though the pattern has been changing in the last few decades, female life expectancy in South Asia still does not exceed that of males by very much, in fact in Bangladesh, Maldives and Nepal, female life expectancy is still lower than that of males despite overall improvements in life chances of females. See Table 2 for gender differentials in life expectancy and trends over time.

Two major features underlie the disadvantage in mortality faced by females in the South Asian region: the first are the high levels of maternal mortality which prevail in most of these countries and the second are sex differentials in mortality in infancy and childhood which disfavour the survival of girls in the postneonatal period and in the period between the ages of one and five. Though both these features may have common roots, that is to say, explanations eventually fall into reasons related to the poor status of women in South Asia, the pathways through which the disadvantage manifests itself are quite different. 
Table 2

Life Expectancy of Females in South Asian Countries:

- Differential with Male Life Expectancy

and Changes Over Time 1970-90

\begin{tabular}{lccc}
\hline & $\begin{array}{c}\text { Female } \\
\text { Life } \\
\text { Expectancy } \\
\left(\mathbf{1 9 9 1 ) ^ { 1 }}\right.\end{array}$ & $\begin{array}{c}\text { Female-Male } \\
\text { Life } \\
\text { Expectancy }^{1}\end{array}$ & $\begin{array}{c}\text { Change in } \\
\text { Female Life } \\
\text { Expectancy } \\
\text { between } \\
1970 \text { and 1990 }\end{array}$ \\
\hline Bangladesh & 52 & -1.0 & 8 \\
Bhutan & 49 & 2.0 & 8 \\
India & 60 & 0.0 & 11 \\
Maldives $^{2}$ & 49.5 & -3.9 & - \\
Myanmar $^{2}$ & 61.8 & 3.5 & 10.8 \\
Nepal & 53 & -1.0 & 11 \\
Pakistan & 59 & 0.0 & 12 \\
Sri Lanka & 74 & 5.0 & 8 \\
\hline
\end{tabular}

Source: ${ }^{1}$ World Development Report (1993).

${ }^{2}$ United NationsThe World's Women 1970-1990 Trends and Statistics. New York, 1991 (Table 5).

\section{EXPLANATIONS FOR THE GENDER DIFFERENTIALS IN MORTALITY IN SOUTH ASIA}

The concern for sex differentials in the South Asian region dates back to 1901 Census of British India. This concern has extended over the years when subsequent Censuses in India, Pakistan, Bangladesh and Nepal have all found an excess of males in the region of 5 to $\mathbf{1 0}$ percent. In fact, recent alarm raised by researchers and other concerned groups about these high sex ratios has been instigated by the fact that mortality levels have fallen in most of South Asia and the sex differentials in mortality continue to persist. With the exception of a handful of countries in Africa and in the Middle East, the pattern of higher female mortality remains almost a peculiarity of this region.

If this pattern of unusual sex differentials in mortality was due to poverty in the region, then rises in per capita income ought to have mitigated these differentials and furthermore other poor regions of the world would have experienced the same pattern. This has not been the case and therefore the explanation seems strongly grounded in the kinship patterns, family structures and position of women 
in this region. It could also be argued that these characteristics have remained relatively unchanged despite some economic and social transformations, which does not auger well as a statement in the favour of any improvement in the position of women of South Asia.

During infancy, the female disadvantage in chances of survival is fairly direct based on the differential behaviour on the part of parents, families and households depending on whosoever is at the centre of decision-making. It can be seen in Table 3 that while boys suffer higher neonatal mortality, from the postneonatal period through until early childhood it is girls who are at a disadvantage. This is because the neonatal period is a time when factors such as congenital malfunctions, neonatal tetanus etc. are largely responsible for deaths and male babies through out the world suffer higher risks of death early in life. However, in the post neonatal period babies are more susceptible to differential care in health and nutrition. Particularly, since most babies in South Asia are breastfed for at least one year, differences in the introduction of supplementary food of boys and girls may be responsible for gender differences in post neonatal mortality. In any event it has been widely argued that this disadvantage of females in the postneonatal stage (one to eleven months) and childhood mortality at ages after one, reflects discrimination in health care and nutrition in favour of males whereas male mortality in the neonatal period is largely attributable to biological factors. It has been argued that regional variations in gender discrimination are a major explanation for the pattern of excess mortality which is dominant in South Asia, and in select countries of West Asia and North Africa [Waldron (1987)]. Such discrimination is observed much less frequently in other regions.

\section{Table 3}

Sex Differentials in Infant-Child Mortality in Selected Countries in South Asia

\begin{tabular}{|c|c|c|c|c|c|c|}
\hline & \multicolumn{2}{|c|}{ Neonatal } & \multicolumn{2}{|c|}{ Post-neonatal } & \multicolumn{2}{|c|}{ Childhood (4g1) } \\
\hline & $\overline{\text { Boys }}$ & $\overline{\text { Girls }}$ & Boys & $\overline{\text { Girls }}$ & Boys & $\overline{\text { Girls }}$ \\
\hline Bangladesh & 86 & 72 & 62 & 58 & 85 & 107 \\
\hline Nepal & 89 & 72 & 69 & 78 & 97 & 114 \\
\hline Pakistan & 90 & 76 & 49 & 70 & 70 & 90 \\
\hline Sri Lanka & 41 & 21 & 23 & 21 & 22 & 25 \\
\hline
\end{tabular}

Source: Rutstein, S. (1984) Infant and Child Mortality: Level, Trends and Demographic Differentials. WFS Cross National Summaries No. 24, Voorburg, Netherlands. 
The discrimination against female children is effected through selective distribution of nutrition as well as health care as is well documented in the South Asian context [Chen et al. (1981); Das Gupta (1987)]. There is some disagreement about whether or not nutritional discrimination may be as important as let's say health care where male children are more likely to receive urgent attention than female children [Harris (1989); Waldron (1987)]. Tables 4 and 5 show empirical evidence from Bangladesh and India demonstrating such discrimination in food, clothing and medicines by gender of children. Although this evidence is specific to these two countries it could well apply to the rest of the region. Even in Sri Lanka where there has been considerable improvement in mortality rates, sex differentials in mortality have only recently narrowed [Langford (1984)].

\section{Table 4}

Daily Intake of Calories and Proteins by Age and Sex in Matlab, Bangladesh (June-August 1978)

\begin{tabular}{crrrrrrrr}
\hline & \multicolumn{3}{c}{ Calories } & & \multicolumn{3}{c}{ Protein in Grams } \\
\cline { 2 - 4 } \cline { 6 - 8 } Age Group & Male & Female & Ratio & & Male & Female & Ratio \\
\hline $0-4$ & 809 & 694 & 1.16 & & 23.0 & 20.2 & 1.14 \\
$5-14$ & 1,590 & 1,430 & 1.11 & & 50.9 & 41.6 & 1.22 \\
$15-44$ & 2,700 & 2,099 & 1.29 & & 73.6 & 58.8 & 1.25 \\
$45+$ & 2,630 & 1,634 & 1.61 & & 71.8 & 46.9 & 1.53 \\
All Agee & 1,927 & 1,599 & 1.20 & & 55.0 & 45.5 & 1.21 \\
\hline
\end{tabular}

Source: Chen, L. et al Sex Bias in Allocation of Food and Health Care in Bangladesh. Population and Development Review 7:1.

\section{Table 5}

Male/Female Ratios of Expenditure on Children's

Clothing and Medicine, by Age of Child

(Punjab, India)

Age of Child

Under 1

$1-4$
Clothing

1.38

2.34

1.37

Medicine

Source: Das Gupta, M. Selective Discrimination Against Female Children in India. Population and Development Review 13:1. 
In the South Asian region, the strong norms against premarital relations lead to strict seclusion of females: this is also a factor which affects the health of young girls due to lack of exercise, curtailment of movement outside the home, restricted growth etc. But above all the danger to adolescent women is the high probability that their families will arrange an early marriage (Table 6) and they will experience a first pregnancy before the age of twenty when they are mere children themselves. Early pregnancies are associated with greater foetal loss, higher infant mortality and many times with adolescent sterility which affects fertility at later ages also.

Table 6

Average Age at First Marriage by Gender in Selected South Asian Countries

\begin{tabular}{lcc}
\hline Country & Female & Male \\
\hline Bangladesh & 16.7 & 23.9 \\
India & 18.7 & 23.4 \\
Myanmar & 22.4 & 24.6 \\
Nepal & 17.9 & 21.5 \\
Pakistan $^{1}$ & 21.7 & 26.5 \\
Sri Lanka & 24.4 & 27.9 \\
\hline
\end{tabular}

Source : Compiled from 1989 World Survey on the Role of Women in Development. United Nations.

${ }^{1}$ NIPS/Institute for Resource Development (1992) Pakistan Demographic and Health Sunvey, 1990-91. Columbia, Maryland.

The health problems of females in South Asia culminate during the peak reproductive years between 15-49. On average women bear 4 to 6 children in quick succession, breastfeed for long durations and have little or no chance to recuperate after each pregnancy. The health hazards they experience are threefold: nutritional depletion weakening their resistance and general health, lack of proper antenatal and postnatal care which could prevent or curtail many health problems and finally, the conditions of delivery, which in the majority of cases are rudimentary, unsanitary, and outrightly dangerous with practically no provision for urgent medical attention in case the pregnancy runs into complications.

The large concentration of births at dangerous ages (too early or too late) and at high parities poses a health risk. Recent rises in the female age at marriage 
in most of South Asia ought to have had a diminutive impact on these risks. But even currently, 55 percent of even married women in Pakistan, 45 percent in Nepal, 82 percent in Bangladesh, become mothers by the age of 20 .

Not surprisingly, South Asia has been singled out as the region where the majority of maternal deaths occur. Out of an estimated 500,000 maternal deaths, 350,000 are estimated to have taken place in South Asia [Boerma (1987)]. Maternal mortality rates are extremely high in this region but especially so in Bangladesh, Nepal, Bhutan and Pakistan while India and Maldives fall in between and Myanmar. Sri Lanka experiences much lower maternal mortality (Table 7).

\section{Table 7}

Matemal Mortality Rates and Related Health Statistics for South Asian Countries

\begin{tabular}{lccc}
\hline & $\begin{array}{c}\text { Maternal } \\
\text { Mortality } \\
\text { Rate }^{1}\end{array}$ & $\begin{array}{c}\text { Percentage of } \\
\text { Births Attended } \\
\text { by Trained } \\
\text { Personal } \\
(1980-87)\end{array}$ & $\begin{array}{c}\text { Percentage } \\
\text { of Pregnant } \\
\text { Women } \\
\text { Immunised } \\
\text { Against } \\
\text { Tetanus }\end{array}$ \\
Country & 600 & 5 & $(1987-88)$ \\
\hline Bangladesh & 770 & 7 & 11 \\
Bhutan & 340 & 33 & 42 \\
India & 330 & 25 & 58 \\
Maldives & 135 & 57 & - \\
Myanmar & 830 & 6 & 24 \\
Nepal & 500 & 24 & 31 \\
Pakistan & 60 & 87 & - \\
Sri Lanka & (1983-88 & 38 \\
\hline
\end{tabular}

Source: 1. WHO Women, Health and Development in the South East Asia Region. Regional Paper, SEARC No. 22. Tables $14,15$.

2. Data for Pakistan are drawn from the Fact Sheet for the Safe Motherhood South Asia Conference, Lahore. Pakistan, March 24-28, 1990.

3. Data for Maldives Drawn from UNICEF Plan of Operation: Programme of Cooperation between the Government of the Republic of the Maldives and UNICEF 1990-94.

There is very little evidence of any rapid recent changes in maternal mortality in the region though the one positive development which is bound to have an influence is the beginning of the fertility transition which has been noted in India 
and Bangladesh. Sri Lanka of course experienced the decline much earlier and remains a forerunner of this region in all respects of the position of women. A life cycle of neglect and discrimination in childhood, followed by a cloistered adolescence, culminating in a long period of pregnancies (many of them unwanted) and endangered deliveries evolves into a vicious cycle where the children of the mothers who bear many children in rapid succession incur additional health risks starting from birth, extending well into their childhood. Low birthweight, retarded development, higher risks of infection are the 'direct' cause of poor health of children from large families and those born when their mothers are either too young, too old, or who are born too quickly after their preceding sibling.

\section{IMPACT ON HEALTH AND FERTILITY: PATHWAYS OF INFLUENCE OF STATUS OF WOMEN}

Much has been written about the role of greater female status and autonomy as a factor in demographic change in the South Asian context. In the context of this region, it has been argued that patriarchal family structures are perhaps the most important feature of the region and reduce the power of women within households and that autonomy of women is exceedingly poor in Northern India as compared to South India, a factor which has lead to faster demographic change in the latter [Caldwell (1986); Caldwell et al. (1990); Dyson and Moore (1983)]. A dependence on sons for old age support is another aspect of the subordination of women in South Asia.

The low position of women in terms of very paltry achievements in education and in terms of their economic contributions not being recognised in official statistics or by households themselves, has been argued to be a factor in the slow pace of fertility change in Pakistan [Sathar et al. (1988)]. Table 8 shows the inverse relationship between female literacy and fertility and infant and child mortality across countries of this region. Both fertility and infant and child mortality are highest in Pakistan and Nepal where female literacy is the lowest, while these indicators are impressively low for Sri Lanka and Myanmar where female literacy is highest in the region.

Women with greater status are expected to be more receptive to modern ideas, have greater exposure to the mass media, are likelier to have broader networks and to have a more 'equal' relationship with their husbands including better communication with them. All these factors will presumably lead to better chances of fertility control within marriage, given that this is desired by the couple. In fact a closer relationship between spouses is bound to be the most critical link 
Table 8

Some Critical Indicators of Female Status and Health for South Asian Countries

\begin{tabular}{lcccc}
\hline & $\begin{array}{c}\text { Adult } \\
\text { Female } \\
\text { Literacy } \\
(1990)^{1}\end{array}$ & $\begin{array}{c}\text { Infant } \\
\text { Mortality } \\
\text { Rate per } \\
\text { 1000 Live } \\
\text { Births (1991) }\end{array}$ & $\begin{array}{c}\text { Child } \\
\text { Mortality } \\
\text { Rate } \\
(1990)^{1}\end{array}$ & $\begin{array}{c}\text { Total } \\
\text { Fertility } \\
\text { Rate } \\
(1991)^{1}\end{array}$ \\
\hline Bangladesh & 22 & 103 & 137 & 44 \\
Bhutan & 25 & 132 & 197 & 5.9 \\
India & 34 & 90 & 127 & 3.9 \\
Maldives & 93 & 68 & 91 & Not Available \\
Nepal & 13 & 101 & 135 & 5.5 \\
Pakistan & 21 & 97 & 139 & 5.7 \\
Sri Lanka & 83 & 18 & 22 & 2.5 \\
\hline
\end{tabular}

Source: ${ }^{1}$ World Bank World Bank Report 1993 (Table 1).

${ }^{2}$ WHO, Women, Health and Development in the South EastAsia Region. Regional Health Paper, SEARO, No. 22 (Table 14).

in determining women's powers to influence important decisions regarding the number of children to have, whether to use contraception etc.

Neither economic nor other material factors can provide the total explanation for the poor health of females in this region. It has recently been recognised that cultural, social and political factors are of notable importance in distinguishing those countries/regions where low mortality has been achieved from those which lag behind as does the South Asia region [Caldwell (1986)]. The lower position of females relative to males in the region and relative to women in other developing countries is a large contributing factor in explaining excessive morbidity and mortality faced by women here. Though religious factors are often cited also, it is the organisation of society, patriarchal kinship systems which lead to the concentration of power of decision-making in the domain of men and the elderly. Where kinship patterns are matriarchal, where the system of dowry is less prevalent, like in the Southern states of India (Karala and Karnataka), the position of women is considered much better than Northern states of Punjab and Rajasthan where patriarchy is more prevalent, and dowry demands are high [Dyson and Moore (1983)]. Child mortality and fertility rates in the former are much lower than in the latter states. 
Though women in Southern Indian States and Sri Lanka do experience a relatively better position than others in this region, progress in achieving a higher status of women in the rest of South Asia is restricted to a small minority of urban women who are educated and who work in modern sector jobs, attributes which are associated with much better health amongst women and children. We concentrate here on those aspects of women's relative position which directly impinge on maternal and child health. The factors which are most critical from the point of maternal and child health are relative mobility of women to gain access to health care facilities if they are available. Strong norms of seclusion in the northern states of India, Pakistan and Bangladesh do not permit such ease of access. Next, the strikingly low levels of educational attainment amongst South Asian women contribute directly to weak information networks and the lack of knowledge of more hygienic and beneficial practices related to child birth and childbearing. Low levels of autonomy of women in personal and household decisions (such as those relating to children's health and schooling), and intrahousehold allocation of resources may be critical amongst the factors culminating in poor female health and higher female mortality in this region.

Lastly, the strong desire for sons over daughters, continues to be a strong motivation for high fertility in South Asia, often explaining an "excess" of children in a family until the desirable number of sons is achieved. This gender preference is largely based on expected economic returns, as women despite their increasing economic roles are not as yet at par with men as earners in South Asia. Further, marriage systems which favour early marriage, high demands of dowry and above all the customary patrilocal residence where a women has little social nor economic connection with her natal home, contributes to the perpetuation of the perception that sons are a much better investment for parents and families than daughters. The alarming reports of the growing prevalence of sex selective testing and subsequent abortions in this region, are another frightening manifestation of the continuing hold of son preference.

\section{STRATEGIES NEEDED TO PROMOTE SAFE MOTHERHOOD}

Ultimately there is no way forward towards achieving better health for women in South Asia until and unless their status in these societies improves-in particular when their work load is reduced, when they are freed from the continuous and self perpetuating cycle of poor nutrition multiple pregnancies in rapid succession, and, when they have greater access to income and education. Only then can they be in control of their own destiny, capable of looking after their health needs 
and those of their children, and to plan to have the number of children they want and to avoid unwanted pregnancies. The enhancement of status of women is intricately related to their legal position, their opportunities of education and access to jobs. The foremost need is for the South Asian countries to invest in female education; the pay offs of such an investment in terms of reducing fertility and in improving women's health are apparent not just by comparisons with other regions but within this region, as in the case of Sri Lanka and Kerala. But in addition Sri Lanka itself proves the point that pervasive education does not necessarily lead to empowerment atleast through employment opportunities given that many of the South Asian economies are facing debt and structural adjustment crisis. Deliberate policies which remove inequalities, discrimination and asymmetry in the employment market are still a prerequisite to improving women's economic situation in South Asia. Ultimately their equal participation in the labour market may be the only factor which will remove the root causes of the poor position of women, such as son preference, seclusion, patriarchy etc.

Although such measures are necessary and do require deliberate policies and greater expenditures on the part of governments, especially on education, income generation schemes etc. they may only take effect in the long run. Several factors which amount to revamping or reshaping existing infrastructures can also be suggested. Some of these are discussed here.

\section{Improving Access}

One of the major features of the South Asian region is the strong desirability of seclusion for females and the resulting limited mobility they experience in leaving their homes. This is a major constraint in their ability to avail of services even if they exist in their vicinity. Thus in this region, increasing access involves not only enhancing physical facilities but also ensuring that these are within what is considered an acceptable distance for women, ensure segregation and female health providers who are dependable and trustworthy. After reviewing programmes related to innovation of $\mathrm{MCH}$ in this region the provision of mobile boats in the sea bound atolls in the Maldives, provision of trained health care workers from the community in the Bangladesh MCH/FP programme, mobile squads in Faisalabad and also better access facilities in the mountainous regions of Nepal are all noteworthy interventions.

Apart from improving physical access and increasing the affordability and quality of services, there is the strongly interconnected issue of strengthening women's role as health providers. The retraining of traditional health providers 
such as the widely utilised TBA's is one possibility. The main advantage in that they are often the only available female health workers in rural areas. However, there are many disadvantages to utilising the services of women who are usually illiterate and who have been administering age old remedies and advice related to maternal and child health care. In that respect, recruiting younger and preferably literate women from the same community as the women they are to serve, may be a more desirable strategy. The benefits of such health providers could be multifold in terms of enhancing the status of the health providers in the eyes of the community and also in terms of being able to have more effective rapport with the women to convince them of the necessity of prenatal and postnatal care and particularly prenatal screening. The same health providers could provide information on beneficial nutritional intakes and could effectively be the "eyes" and "ears" for any health interventions (whether vertical but preferably integrated) to implemented successfully at the grass root level.

\section{Information, Education and Communication}

Another major aspect of the poor status of women in South Asia are their limited channels of information. Education and employment outside the home are tow possible avenues on increasing awareness and knowledge of health seeking behaviour and of means of controlling fertility. However in the case of an average woman in South Asia it is a case of being, ill informed woman, unaware of where to go and when to seek health care for herself and her children. In all likelihood the family is generally unsupportive and the surrounding community lacks the awareness or knowledge to take care of its health needs. The majority of women in South Asia are surrounded by ignorance and lack of information about prevention of disease and deaths.

Apart from the long term strategy of education for all females, (whose importance is especially integral for mothers as major health providers of the family), much can be achieved by strategies of transmitting simple health education through adult literacy or other schemes, such as long distance learning on the radio or television and by community education schemes. Rather than targeting women solely as those responsible for their own health care needs, it would be much more realistic and far more effective to target atleast the family if not the community in terms of providing critical information about women and children's health needs. This is in light of the earlier discussion which clearly states that women's restricted position, vis à vis their mobility and especially autonomy in the household, is a hindrance to their being able to take positive action towards improving their health 
and that of their children.

Thus, families in general and major decision-makers i.e. mothers and fathers in law and husbands in particular, need to be appraised of the importance of the special nutritional, and healthcare needs (particularly preventive health care such as immunisation and prenatal screening) of women. It is even more critical that family members and women themselves are made aware of many danger signs (swelling of hands, bleeding, fits etc.) which should trigger off in them the signal that they ought to take the women to the nearest hospital or health care facility. It is important to emphasise that they ought not to hesitate or to be indecisive in the face of such warning signs and a delay in transporting women to a hospital may be the difference between life and death!

Though the sympathy of families may be critical in terms of life saving decisions, much can be achieved by women themselves especially in the way of preventive measures involving primary healthcare. Networking between women, especially the formation of women's groups and organisations along the lines of Grameen Bank in Bangladesh, and SEWA in India can be a forceful vehicle for women to came together, discuss and share information on their health concerns and needs.

\section{Integration of Family Planning Programmes and MCH}

Particularly since the majority of South Asian women face obstructions in taking independent decisions to control their fertility they would be in a much stronger position if they were to seek such advice and facilities under the auspices of health care facilities. Of all available shorter term measures, family planning programmes in South Asia have the greatest potential to improve the health and life chances of women and children in this region. This can be done by reducing pregnancies among women of unfavourable ages, unfavourable parties and in situations of unfavourable obstetric histories. In addition, family planning can reduce the number of unwanted pregnancies that would result in illicit abortion, which is in this regions' conditions, are always life threatening and by reducing the sheer number of births!

It is desirable to delay first births by delaying marriages and to promote birthspacing of atleast four years between children by non-terminal contraceptive methods through an effective family planning programme integrated with $\mathrm{MCH}$ facilities. Though, almost all the South Asian countries do have an official family planning programme intended to provide services to women who do not want to have any more children or to space them more deliberately, a substantial proportion 
of married women aged 15-49 in South Asia (ranging from 40 percent in Sri Lanka to 62 percent in Bangladesh) say they want no more children but are not using any form of contraceptives. Success in family planning in this region has been limited. Clearly there is a gap between supply and demand in this region and though a complex issue, one of the major constraints are the taboos against the use of family planning methods as anti-religion, anti customary, anti-societal and 'unnatural'. An integrated approach fully capitalising on convincing families of the advantages of saving a mother's life and improving her health or the health and welfare of her children and the direct advantages in terms of health and life chances of children (if they are properly spaced and do not have too many siblings), may be an important and critical argument for the greater utilisation of both family planning and $\mathrm{MCH}$ facilities. In South Asia, in particular, it would be definitely easier for women to utilise an MCH/FP facility rather than a solely family planning facility due to reasons of inhibition, mistrust, shame, hesitation etc.

\section{Data Gaps}

Last but not least, is the strong and immediate need to provide accurate, representative and relevant data on maternal health and mortality. Whereas the international community recognised, more than a decade ago, the need for such data and information on child health and mortality, the recognition for adequate data on women's health indicators, (particularly maternal morbidity and mortality) has not been as forthcoming.

Most of the data that are available for South Asia are based on small micro-level studies based on small sample areas and are not representative of the whole population. National estimates for maternal mortality and morbidity are therefore based on "guess estimates" with large variation in the rates available for each country. With the exception of Sri Lanka, most of the South Asian countries cannot claim any single reliable estimate for maternal mortality which applies nationally. Efforts to bridge these glaring gaps in information and to resolve the sometimes rather irreconcilable differences in available estimates, has to be one of the urgent priorities of this region. Without knowing the regions and, the subgroups where maternal health is weakest and most neglected it will be difficult to target special groups and to proceed with many of the initiative proposed above.

\section{REFERENCES}

Boerma, J. T. (1987) Levels of Maternal Mortality in Developing Countries. Studies in Family Planning 18:4. 
Caldwell, J. C. (1986) Routes to Low Mortality in Poor Countries. Population and Development Review 12:2.

Caldwell, J. C. et al. (eds) (1990) What We Know about Health Transition. Canberra: Health Transition Centre, the Australian National University.

Chen, et al. (1981) Sex Bias in Allocation of Food and Health Care in Bangladesh. Population and Development Review 7:1.

Das Gupta, M. (1987) Selective Discrimination Against Female Children in India. Population and Development Review 13:1.

Dyson, T., and M. Moore (1983) Kinship Structure, Female Autonomy and Demographic Behaviour in India. Population and Development Review 9:1.

Harris, B. (1989) Differential Female Mortality and Health Care in South Asia. Journal of Social Studies 44.

Langford, C. (1984) Sex Differential in Mortality in Sri Lanka: Changes Since the 1970s. Joumal of Biosocial Sciences 16.

Sathar, et al. (1988) Women's Status and Changes in Fertility in Pakistan. Population and Development Review 14:3.

Waldron, I. (1988) Patterns and Causes of Excess Female Mortality among Children in Developing Countries. World Health Statistics Quarterly 40:3.

World Bank (1990) World Development Report 1990. Washington, D. C.: World Bank. 


\section{Comments on \\ "Safe Motherhood in South Asia: \\ Current Status and Strategies for Change"}

\section{BACKGROUND}

The paper describes the sad plight of South Asian women in the context of safe motherhood, and proposes strategies which could possibly improve it.

The paper points to the gender differential in mortality in South Asia, and argues that it is not due to poverty but is attributable to kinship patterns, family structures and, especially, the low position of women in the region. The unusual sex differentials in mortality support the assumption. Mortality is higher among baby girls because of deliberate discrimination and neglect in nutrition and health care. Seclusion of females, it is stated, affects their health, and poorer health is perpetuated by illiteracy and ignorance. In addition, early and unbridled fertility generates health hazards during the reproductive years, and consequently, maternal mortality remains high. The assumption is that "the lower position of females.... is a large contributory factor in explaining excessive morbidity and mortality faced by women here". Confounding the issue is the strikingly low level of female educational attainment contributing directly to a lack of knowledge of beneficial practices.

Family planning (FP) programmes are proposed as a short-term measure having the greatest potential to improve the health and life chances of women and children in the region. In addition to the benefits of regulated fertility, it is claimed that such programmes could also help delay marriages and promote birth spacing. It is pointed out, though, that despite a desire to stop child-bearing, a large proportion of women is not using contraception.

Finally, the paper brings out the issue of data gaps, and points to the need to provide accurate, representative and relevant data, instead of "guesstimates", on maternal health and morality.

\section{DISCUSSION}

The central problem addressed by the paper-the low status of South Asian women-is not only of extreme importance, but is indeed a major issue with many 
dimensions and implications. The paper discusses its negative effects on the health of women and their children, and suggests some remedial strategies. The strategies proposed, particularly FP programmes, however, are not new to Pakistan. They have been, and continue to be implemented in the country through several different schemes and projects.

Among the countries of the region, Pakistan has yet to experience any dramatic declines in fertility. It is claimed that whatever little decline in fertility has occurred is due to a rising age at marriage. In this context, two factors need to be examined.

Firstly, breast-feeding and how much reduced periods of breast-feeding are off-setting the gains made through a rise in marriage age. Secondly, the claim that the contraceptive prevalence rate is much higher than the 14 percent quoted as there is a 'shy element' comprising women too shy to openly state that they are using contraceptives. Is the traditional timidness of Pakistani women a cause or a result of her low status?

The foremost need, albeit effective in the long run, is to invest in women's education. However, as the attitude and behaviour of men are claimed to be contributing to the low status of women, simultaneous action to address this issue is of equal importance. The policy and strategies of the national Population Welfare Programme have seen several changes on the basis of experience gained over the years, and informational, educational and promotional activities have strongly supported the Programme. Yet, a change in male attitudes is not evident.

The paper points to the need for women to be freed from the continuous and self-perpetuating cycle of poor nutrition and multiple pregnancies in rapid succession, and the need to have access to income and education. Access would be improved with greater mobility of women, and making services available within easy reach through female providers such as TBAs, or community women. The paper advocates stronger IEC activities to not only provide information but seek the support of family and community for women's health needs. A good suggestion is to make family members and women themselves aware of danger signs so that medical assistance is sought in time. Networking among women is recommended as an effective vehicle for women to come together, and discuss and share information on their health concerns. The role of NGOs in making such an approach effective needs to be explored.

Informational and educational programmes must focus on the issues raised in the paper of seclusion of women, their restricted mobility, and lack of access to health care, which are cited as factors contributing to the low status of women. 
Not only women but men need to be educated about women's rights, and the absolute necessity of giving women those rights.

The final point brought out in the paper is the need for good, reliable data. There can be no two opinions on that as accurate data are essential at each step from planning, to implementation, resource allocation, etc. and for determining and monitoring socio-economic indicators. Also, Pakistan needs to disseminate better data to the world community.

In Pakistan, several different strategies to raise the status of women have been tried in the past but without satisfactory results. The point to ponder, therefore, is the non-impact of all these programmes. What researchers need to look at is why has there been no significant change. Several questions come to mind. What further change is needed in the tried and tested strategies being executed currently for socio-economic development in general and raising women's status in particular? If demand for family planning exists, then where is it and why is it not being fulfilled? What will make a difference to fertility change and thence status of women at the macro level, and what at the micro level? How can peopleboth men and women, young and old-be made to think, and more importantly act differently? How can negative social norms and practices as well as traditions be changed? Is it a social responsibility or is to a responsibility of the individual? Does attention alone to parental characteristics such as education, knowledge and low fertility place unrealistic expectations on parents, particularly mothers? What is or can be the role of other social institutions? And of privatisation? What "mix" of socio-economic development and organised family planning programmes is needed? We need to think, and we need to act effectively as surely our women deserve a better deal.

Ministry of Population Welfare,

Sajida Samad

Islamabad. 